\title{
POLÍTICAS DE DESENVOLVIMENTO RURAL NO URUGUAI PROGRESSISTA: 2007-2011
}

\author{
RURAL DEVELOPMENT POLICIES IN URUGUAY \\ PROGRESSIVE: 2007-2011
}

\author{
José Pedro Cabrera Cabral \\ Universidade Federal do Tocantins - Palmas - TO - Brasil
}

\begin{abstract}
Resumo: Este artigo aborda as políticas públicas de desenvolvimento rural adotadas pelo governo uruguaio no período de 2007 a 2011 desde a perspectiva do ordenamento territorial. O objetivo da pesquisa focou-se no novo modelo de desenvolvimento do governo progressista. A hipótese central foi que o governo progressista uruguaio implementou um novo modelo de desenvolvimento rural para beneficiar os setores agroexportadores e o capital internacional. A análise foi realizada a partir de documentos elaborados pelo governo no período mencionado. Os resultados apontam para quatro elementos-chave. O primeiro, refere-se a uma nova configuração das políticas de desenvolvimento rural no país com base numa "nova" institucionalidade criada pelo governo para o desenvolvimento rural. O segundo, centra-se na lógica do ordenamento territorial como elemento legitimador do novo modelo de desenvolvimento. O terceiro demonstra como o governo de esquerda focou suas políticas de desenvolvimento sob a lógica do desenvolvimento econômico territorial, e o quarto elemento versa sobre como os problemas históricos sobre o uso e a propriedade da terra continuam sem solução, tomando agora uma nova dimensão.

Palavras-chave: Ordenamento Territorial. Desenvolvimento. Questão Agrária.
\end{abstract}

\begin{abstract}
This article studies the rural development policies adopted by the Uruguayan government progressive in the period 2007-2011. The research investigated the new development model driven by progressive government. The central hypothesis is that progressive Uruguayan government implemented a new model of rural development to benefit the agroexporters sector and international capital. The analysis was conducted from documents prepared by the Uruguayan government in the period 2007-2011. The results indicate four basic themes: the first relates to a new configuration of rural development policies in the country based on a "new" institutionality created by the government for rural development, the second focuses on the logic of spatial planning as legitimizing element of the new development model, and the third shows how the leftist government focuses its development policy on the logic of economic development and territorial; fourth theme as historical issues regarding the use of property and land ownership not only remain unsolved, but also gain a new dimension.
\end{abstract}

Keywords: Territorial Planning. Development. Agrarian issue.

\section{INTRODUÇÃO}

A esquerda uruguaia que chegou ao governo nacional em 2004, chamada de "esquerda progressista", originou-se no processo de redemocratização ocorrido a partir da metade da década de 1980. Essa nova esquerda, fruto de uma atualização ideológica ocorrida no interior da esquerda eleitoral uruguaia, reformulou os conteúdos ideológicos, programáticos e estratégicos da coalizão "Frente Ampla", o que Ihe possibilitou adequar-se aos novos tempos para, pela

\footnotetext{
${ }^{1}$ Artigo resultante de projeto de pesquisa desenvolvida na Universidade Federal do Tocantins no curso de Mestrado em Geografia, linha de pesquisa: Estudos Geo-Territoriais. Este estudo foi financiado pelo CNPq - Conselho Nacional de Desenvolvimento Científico e Tecnológico - Brasil.
} 
primeira vez na história do país, ascender ao governo nacional, quebrando, assim, o bipartidarismo secular e transformando-se na maior expressão eleitoral no âmbito nacional.

Essa atualização ideológica implicou no abandono das tradicionais bandeiras da esquerda que foram construídas historicamente por amplos setores populares e que representavam as reivindicações que marcaram as lutas populares durante o século XX no país: a reforma agrária redistributiva, a nacionalização do sistema bancário e o não pagamento da dívida externa, entre outras. O tema da reforma agrária, em particular, era uma proposta ampla e avançada que almejava uma reforma redistributiva coletiva da terra e questionava seriamente a propriedade privada da terra, sobretudo o latifúndio que, em seu entendimento, deveria ser expropriado.

Desde a segunda metade da década de 1990, gradativamente, essas reivindicações passaram a representar uma expressão mínima no discurso da esquerda eleitoral uruguaia até desaparecerem das plataformas políticas e dos programas de governo a partir de 2004. A atualização ideológica varreu do cenário político do país toda a discussão político-ideológica de sustentação da esquerda tradicional, ou seja, toda a teoria crítica e as contribuições a esta relacionadas. Em seu lugar, elaborou-se um discurso social-democrata raso, esvaziado de conteúdos críticos e que baseia suas análises em novos elementos fundantes da nova esquerda: em lugar da análise política tudo se passou a explicar pelo viés cultural; no lugar da análise econômica, o discurso de mercado assumiu como o novo lócus desta nova esquerda.(CABRAL, 2008).

Cultura e mercado são os novos conceitos que permeiam os discursos da esquerda uruguaia, servindo de base para suas novas propostas programáticas de governo. O ethos neoliberal marcou definitivamente uma esquerda que queria chegar ao poder e, para isso, teve que incorporar os valores e discursos do neoliberalismo, o que conflitava frontalmente com as antigas reivindicações da esquerda tradicional. A incorporação de todo o arcabouço discursivo empresarial se faz presente na esquerda progressista: gestão estratégica, competitividade, eficiência, eficácia, produtividade, flexibilidade, atores sociais, agentes de desenvolvimento, entre tantos outros.

O tema do desenvolvimento regional, impulsionado fortemente pela lógica neoliberal desde a década de 1990, encontra-se em pleno auge no Uruguai atual. Inúmeros programas e projetos, "recomendados" e financiados pelo Banco Mundial, vêm sendo executados para proporcionar um "desenvolvimento para todos", segundo o discurso do governo. Esses programas se constituíram em bases do Programa de Governo de Tabaré Vásquez, em 2004, e continuam sendo desenvolvidos pelo governo de José Mujica.

Os desdobramentos dos programas de desenvolvimento regional em desenvolvimento territorial e desenvolvimento rural são o objeto de análise do presente artigo. A proposta é observar como essa nova esquerda se configura, a partir de 2004, alinhada aos organismos multilaterais e, junto com eles, desenham e colocam em prática um novo modelo de desenvolvimento rural para o país. Que desenvolvimento é esse? Como isso acontece? Quem se beneficia com essa 
proposta de desenvolvimento? Essas são algumas das perguntas que norteiam nosso trabalho.

\section{O INICIO DE UMA NOVA INSTITUCIONALIDADE}

O primeiro Encontro Nacional da Produção Agropecuária Familiar, em setembro de 2007, realizado na cidade de Tacuarembó, foi organizado pelo Ministerio de Ganaderia, Agricultura y Pesca - MGAP. Com a participação de José Mujica, como ministro, reuniram-se representantes do governo, movimentos sociais, organizações sindicais rurais, associações e cooperativas de produtores e trabalhadores assalariados rurais. O objetivo do encontro era o de fortalecer 0 "diálogo" entre o governo, os produtores e associações rurais, com a intenção de somar esforços para o fortalecimento da agropecuária familiar. (GONZÁLES; GÓMEZ, 2007).

Observe-se que a convocatória desse encontro estava dirigida à "agropecuária familiar", envolvendo, assim, "agricultores familiares", como também "pecuaristas familiares". Essa junção de categorias se fez possível a partir do argumento governamental de que, no Uruguai, existe uma grande quantidade de pequenos produtores "familiares" que se dedicam à produção leiteira. Estes produtores, geralmente, estão organizados a partir de associações e cooperativas.

O encontro teve como modalidade o debate por eixos temáticos. Os temas foram: i) o acesso à terra; ii) financiamento; e iii) comercialização dos produtos da agropecuária familiar. O primeiro grupo, tendo como tema "o acesso à terra", desdobrou-se em três eixos de discussão: a) o papel do Instituto Nacional de Colonização; b) a estrangeirização da terra; e c) a concentração da propriedade da terra. Vejamos, resumidamente, o teor dos debates.

a) Ao Instituto Nacional de Colonização: criticou-se a falta de divulgação da lei de colonização em todos os seus termos. Discutiram-se critérios de prioridade para o acesso à terra como, por exemplo: para mulheres chefes do lar, para trabalhadores rurais, para jovens e para grupos associativos. Apontou-se para a necessidade de maiores investimentos por parte do governo para a aquisição de terras para distribuição.

b) A estrangeirização da terra: o tema surgiu como preocupação central nas discussões. As propostas objetivavam colocar um freio nesse processo. Os debates se focaram em: i) que os filhos de estrangeiros não residentes não possam herdar a terra; ii) que não se possa adquirir terra por parte de estrangeiros numa faixa de até $50 \mathrm{~km}$ da fronteira; iii) que se estabeleça um sistema tributário diferenciado para estrangeiros; e iv) que os proprietários da terra sejam pessoa física, não podendo ser sociedades anônimas.

c) A concentração da propriedade da terra: vinculado aos temas anteriores, o debate teve como foco a possibilidade de se limitar o número de hectares possíveis de serem objeto de propriedade de uma única pessoa, em função da realidade socioprodutiva de uma determinada região. Também se debateu a 
necessidade de regularizar o mono cultivo, assim como, estabelecer limites para o florestamento e a soja.

O segundo eixo de debates do encontro teve como tema o financiamento. Destacou-se, basicamente, que o sistema financeiro formal não era adequado para a produção familiar e que se encontravam sérias dificuldades no seu acesso: requisitos legais, garantias exigidas e linhas de financiamento que não atendem às particularidades do produtor familiar. As propostas se direcionaram para a necessidade de criar políticas de financiamento diferenciadas para a produção familiar. Estas políticas deveriam definir: taxas de juros diferenciadas, seguros, prazos e perfil do crédito conforme os ciclos produtivos.

O terceiro eixo - comercialização dos produtos da agropecuária familiar discutiu uma ampla variedade de problemas a partir de diversas realidades produtivas. Os temas incluíram a informalidade, as normas sanitárias, a coletivização da produção, formas de pagamento diferenciadas, o papel dos intermediários nos processos produtivos, o ingresso de produtos estrangeiros e 0 contrabando. Colocou-se a necessidade de criar um registro de produtos familiares. Surgiu uma proposta que visava incentivar a compra de produtos familiares pelo Estado, como forma de garantir mercado para estes produtores (GONZÁLES; GOMEZ, 2007, p. 279 - 283).

Segundo o governo progressista, como resultado dos debates ocorridos no âmbito da Produção Agropecuária Familiar, se acelerou o processo de descentralização no segmento. A partir da aprovação da Lei 18.126, de 12 de maio de 2007, iniciou-se o processo de descentralização agropecuária. Em pouco mais de um ano de sua promulgação, colocou-se em funcionamento toda uma estrutura descentralizada em nível nacional. Os Conselhos Agropecuários foram instalados em todos os departamentos do país. A finalidade destes Conselhos era a de inter-relacionar as políticas nacionais com as políticas departamentais, articulando-as com as políticas municipais.

Paralelamente à implantação dos conselhos departamentais, foi criada uma instância regional-territorial, chamada de Mesas de Desenvolvimento Rural. Essas mesas seriam a ponta do processo de descentralização, ou seja, é onde se efetivariam as demandas locais a partir das diversas organizações da sociedade civil que as compõem: sindicatos, associações e cooperativas de produtores, grupos de produtores em fase de organização e trabalhadores assalariados.

Os primeiros passos governamentais para o desenvolvimento rural territorial foram dados a partir da Lei 17.930, de 01 de abril de 2008, com a criação da Direção Geral de Desenvolvimento Rural - DGDR, com o objetivo de organizar projetos e programas de desenvolvimento rural no âmbito do $M G A P$, com a finalidade de integrar suas ações com o Instituto Nacional de Colonização - INC, procurando construir uma nova relação de cooperação para potencializar estratégias de desenvolvimento rural com enfoque territorial. Para tanto, foi criado um Plano de Desenvolvimento com enfoque territorial com as seguintes bases: i) dar apoio ao aparelho produtivo da agricultura familiar; ii) fomentar a institucionalidade; e iii) articular os serviços (VASSALLO; TADDEO, 2009). Entre 2008 e 2010, vários projetos e programas se colocaram em marcha até a 
aprovação da lei de Ordenamento Territorial, que passou a ser um novo marco para o desenvolvimento rural.

A dois anos da realização do I Encontro dos Produtores Familiares, o governo progressista organizou o II Encontro Nacional da Produção Familiar. Este aconteceu em setembro de 2009, na cidade de Sauce, no departamento de Canelones, também organizado pelo MGAP. O evento contou com a participação de trezentas organizações de todo o país. O tema central do encontro foi o impacto gerado na produção familiar pelo avanço do agronegócio no Uruguai nas últimas três décadas.

\begin{abstract}
Neste contexto, os processos organizativos da produção agropecuária familiar são algumas das chaves para sua sobrevivência. Os produtores familiares têm sido fortemente afetados pelas políticas das últimas décadas que estimularam a concentração da terra e a riqueza no agronegócio, processo que, paralelamente, enfraqueceu os processos organizativos, diminuindo a capacidade de estas organizações constituírem-se em atores fortes para a negociação com as agroindústrias, o Estado e/ou outros atores vinculados (GONZÁLEZ, 2009, p. 417).
\end{abstract}

Segundo o governo, a nova institucionalidade, criada a partir da Direção Geral de Desenvolvimento Rural, tinha como cometido superar os problemas existentes em relação ao avanço do agronegócio e, para esse fim, as Mesas de Desenvolvimento Rural - MDR eram, justamente, as instancias próprias para fortalecer a autogestão nos diversos territórios. Segundo as conclusões dos grupos de trabalho do II Encontro, as MDRs tinham um caráter essencialmente consultivo, propondo-se como mecanismo de avanço para a descentralização. Tanto a nova institucionalidade como as MDRs não resolveram os antagonismos entre produtores familiares e o agronegócio.

As propostas que se apresentaram sobre o tema da agroindústria focaram procurar melhorias nas relações entre a indústria e os produtores nas diversas cadeias, objetivando uma melhor distribuição do lucro entre os diversos componentes dessas cadeias, garantindo, assim, que o produtor "não perderá sempre". A derrota dos produtores está estampada na frase: "o que resta por fazer é negociar com a agroindústria" - por meio da mediação do Estado - para que as perdas não sejam tão grandes.

Em relação às outras temáticas discutidas no Primeiro Encontro, em 2007, os casos do acesso ao financiamento e o acesso e posse da terra continuaram se apresentando como preocupações básicas dos produtores familiares, ou seja, não houve avanços significativos sobre estes temas. O foco do II Encontro mudou em relação ao I Encontro: no primeiro, a proposta tinha como base a identificação dos problemas existentes na produção familiar e a elaboração de estratégias para sua superação; no segundo encontro, a estratégia por excelência foi a "negociação", dependente e subordinada, com o causador do problema: a produção da agroindústria.

Como ilustração de nossas observações, veja-se o Quadro 1 abaixo. 
Quadro 1. Caracterização dos Produtores Agropecuários médios e grandes produtores e agricultura familiar - 2008

\begin{tabular}{|l|c|c|c|c|}
\hline & $\begin{array}{c}\text { Produtores } \\
\text { Familiares }\end{array}$ & $\%$ & $\begin{array}{c}\text { Médios e } \\
\text { Grandes } \\
\text { Produtores }\end{array}$ & $\%$ \\
\hline $\begin{array}{l}\mathrm{N}^{\circ} \text { de } \\
\text { Estabelecimentos }\end{array}$ & 32.696 & 63 & 19.415 & 37 \\
\hline $\begin{array}{l}\text { Superfície } \\
\text { Explorada }\end{array}$ & 2.522 .850 & 15 & 13.875 .896 & 85 \\
\hline
\end{tabular}

Fonte: Elaboração própria a partir de dados do MGAP. In: Anuário OPYPA, 2008.

Os dados demonstram como é significativa a concentração e o uso da terra: apenas $15 \%$ da superfície explorada do território nacional uruguaio está nas mãos da agricultura familiar, enquanto que $85 \%$ pertence a médios e grandes produtores. Deve considerar-se, ainda, que esses dados são de 2008 e, segundo estudos realizados na Faculdade de Agronomia da Universidade da República entre outros -, o avanço do agronegócio já modificou esta realidade e as estimativas são de que, em 2012, aproximadamente $11 \%$ da superfície ocupada corresponde à agricultura familiar e, portanto, $89 \%$ se vincula aos médios e grandes proprietários.

O governo progressista entendia que as empresas agropecuárias tinham um papel fundamental para o desenvolvimento rural. Em 2008, o senhor Robert Frugoni, diretor da Direção Geral de Desenvolvimento Rural, manifestou a opinião do governo sobre as empresas agropecuárias: "Constituem o primeiro elo das cadeias agroindustriais e são fator fundamental na formação do Produto Interno Bruto - PIB e necessitam de políticas definidas que permitam seu desenvolvimento, superando o simples crescimento de sua atividade" (FRUGONI, 2008, p. 257).

Frugoni definia, então, qual era o foco do desenvolvimento rural proposto pelo governo progressista. Quando ele fala em empresas agropecuárias, entendase, agronegócio. Neste, estão contempladas as médias e grandes empresas (ver seu significado no quadro anterior) e, obviamente, excluídas as pequenas propriedades. Frugoni apresentou as ações e estratégias que o governo tinha para atender às empresas agropecuárias: a) Maior organização e recursos destinados a preservar o status sanitário atingido pelo país, com enfoque nacional e regional; b) Instalação e desenvolvimento de um sistema que assegure o acesso e permanência de nossos produtos exportáveis nos mercados mais exigentes; c) A produção nacional deve avançar na elaboração e aplicação de um manual de boas práticas agrícolas para fortalecer a posição de nossos produtores no mercado; d) Apoio e fortalecimento de instâncias de coordenação e promoção do setor agroindustrial, com o objetivo de desenvolver maior competitividade nas cadeias, por meio de diferentes âmbitos, com o recentemente criado Gabinete Produtivo; e) Fortalecer as cadeias agroindustriais, procurando uma maior transparência na distribuição da renda entre todos seus atores e a geração de maiores externalidades positivas na sociedade; f) Apoio decidido à pesquisa para a geração de tecnologias, procurando melhorar a competitividade e incorporar mais trabalho nacional e sua aplicação e, 
especialmente, diminuir o consumo de energia em todas as fases do sistema produtivo; g) Procurar novos mercados e melhores oportunidades de acesso aos mesmos; h) Defesa dos direitos adquiridos nas negociações internacionais referidas ao acesso a mercados, taxas e subsídios; i) Trabalhar junto às cadeias agroindustriais procurando estratégias de desenvolvimento que permitam a todos os setores algo além do mero crescimento; j) Apoio para a instrumentação e concretização das obras que se definam como de "interesse nacional" para o desenvolvimento agropecuário; k) Definir investimentos e áreas de interesse no meio rural dentro do marco estratégico do Desenvolvimento Rural (FRUGONI, 2008, p. 260 - 263).

Quando o diretor da DGDR afirma que as empresas agropecuárias (ou seja, o agronegócio) são uma peça fundamental para a composição do PIB ele está coberto de razão. Observe-se, no Quadro 2, a seguir, os dados relativos ao triênio 2009-2011:

Quadro 2. Composição do PIB agropecuário no triênio 2009-2011

Em bilhões de dólares - USA

\begin{tabular}{|c|c|c|c|}
\hline ANO & 2009 & 2010 & 2011 \\
\hline PIB Total & 20.032 & 23.959 & 31.199 \\
\hline PIB Agroindustrial & 2.602 & 3.069 & 4.474 \\
\hline PIB Agropecuário & 1.673 & 2.049 & 2.873 \\
\hline $\begin{array}{c}\text { PIB de Indústrias } \\
\text { Associadas }\end{array}$ & 929 & 1.019 & 1.601 \\
\hline
\end{tabular}

Fonte: Elaboração própria a partir do Anuário Estatístico do período. INE, Montevideo, 2009 2011.

O Instituto Nacional de Estatísticas uruguaio-INE entende por indústrias associadas os setores produtivos vinculados à produção de madeira para a fabricação de móveis e couros industrializados em diversos produtos. Pode-se observar um substancial aumento do PIB no triênio. Lamentavelmente, a parte dessa composição que corresponde às pequenas propriedades, assim como à agricultura familiar, não está identificada nas estatísticas do INE. Sabe-se que estas categorias se encontram diluídas no item PIB Agropecuário, mas se desconhece sua incidência. Obviamente, a pequena produção não é responsável pelo significativo aumento obervado no setor. Agora, a pergunta é: como se legitimam e se regulamentam as políticas voltadas para a promoção e defesa da agroindústria no Uruguai? O discurso legitimador parte do arcabouço criado a partir do ordenamento territorial. Observe-se como isso ocorre.

\section{A LEI DE ORDENAMENTO TERRITORIAL E DESENVOLVIMENTO SUSTENTÁVEL}

A lei de Ordenamento Territorial e Desenvolvimento Sustentável utiliza uma definição pouco clara do conceito de território. Em 2010, O Ministerio de 
Vivienda, Ordenamiento Territorial y Medio Ambiente - MVOTMA elaborou um documento com diretrizes nacionais de ordenamento territorial e desenvolvimento sustentável com o objetivo, entre outros, de conceituar o território em questão. A Constituição Uruguaia define a República como a associação política de todos os habitantes compreendidos dentro de seu território. Assim, o território compreende seus habitantes.

\begin{abstract}
O território, resultado dessa relação única e necessária que se estabelece entre um coletivo social e uma área determinada da superfície terrestre, é por natureza uma formação dinâmica: se desenvolve e se transforma permanentemente, tanto no tempo como no espaço. Não existem territórios terminados. Tampouco territórios iguais. O território sempre se materializa em termos dinâmicos, singulares e irrepetíveis (MVOTYMA, 2010, p. 2).
\end{abstract}

Segundo os intelectuais do governo progressista, a condição material do território evidencia sua natureza histórica, visto que também é o resultado da acumulação do trabalho social ao longo do tempo. A natureza espacial do território faz o lugar de dita materialização e, dessa forma, inevitavelmente, deve ser pensado como o resultado provisório dos equilíbrios de sua relação fundadora.

\begin{abstract}
O ordenamento do território estabelece fins e em função deles constitui políticas. Não se trata de um conjunto de instrumentos técnicos neutrais. Como a sociedade que o habita, o território é âmbito de projetos contraditórios e inclusive opostos. As ações empreendidas no território conduzem a resultados algumas vezes esperados e outras vezes não. Nada indica que o território tenha que ser uma eterna cópia de si mesmo (MVOTYMA, 2010, p 13).
\end{abstract}

O marco conceitual do desenvolvimento territorial é inexistente. O que melhor se aproxima no discurso do governo progressista uruguaio a este respeito é o conceito de desenvolvimento econômico endógeno adaptado ao território. Mesmo não existindo um enfoque territorial endógeno de desenvolvimento econômico como corpo teórico de consenso, a convergência de vários enfoques teóricos do desenvolvimento local se direciona para o desenvolvimento territorial. Assim, o local passa a ser o território e o regional, ou território "ampliado," passa a se articular com outros territórios.

O arcabouço conceitual do desenvolvimento endógeno local é formado por várias correntes teóricas e, dentre estas, se destacam as obras de Barqueiro (2002, 2005) e Becattini (2002) que argumentam a favor da inovação como elemento chave para o desenvolvimento, seguindo uma linha neochumpetiana. Somando-se a estes, o enfoque de clusters, a partir de Markusen (1996) e Porter (1991) e as contribuições da teoria econômica espacial tradicional com autores como Von Thunen, Losch e Keilbach (2000), junto à nova geografia econômica de Krugman (1991, 1995, 1996). Essas teorias, entre outras, serviram de base aos governos uruguaios para elaborar políticas públicas de desenvolvimento local e regional no âmbito rural nos últimos 20 anos. 
Essas diversas correntes teóricas possibilitaram transitar desde a visão tradicional do crescimento econômico, de caráter exógeno e macro setorial, para um enfoque territorial endógeno de desenvolvimento econômico. Dois elementos centrais que se abstraem dos diversos enfoques teóricos convergem no conceito de desenvolvimento econômico territorial: o primeiro, a importância da dimensão territorial e, o segundo, o caráter endógeno do processo. Miranda e Sienra (2008) definem claramente o conceito de desenvolvimento econômico territorial:

o desenvolvimento econômico de um território (regiões, localidades ou cidades) refere-se a um processo endógeno de acumulação de capital que depende do desenvolvimento do potencial competitivo do sistema produtivo local que, por sua vez, depende da capacidade empresarial local, da forma em que os empresários e agentes organizam-se para produzir, da introdução e difusão de inovações, do papel das economias de acumulação (associado ao papel das cidades do território e a suas regiões de influência) e do marco institucional onde tudo isso ocorre (MIRANDA: SIENRA, 2008, p.22 - 23).

A partir dessa definição, pode-se tomar quatro elementos-chave para o desenvolvimento econômico territorial: a inovação, a organização da produção, as economias de acumulação e as instituições. Segundo Miranda e Sienra (2008), entende-se que esse desenvolvimento deve ser visto como o resultado da interação sinérgica dos quatro elementos. Assim, o desenvolvimento econômico territorial deve integrar necessariamente a todos e a cada um destes fatores e, particularmente, a interação entre eles.

O modelo de desenvolvimento territorial uruguaio foi elaborado a partir da lógica neochumpetiana e todos os elementos apontados acima, em particular, os quatro pontos-chave para o desenvolvimento territorial estão presentes no discurso do governo progressista uruguaio. A proposta de desenvolvimento, mais uma vez, fundamenta-se sobre o crescimento econômico tão combatido outrora pelos mesmos progressistas de hoje.

A análise do território uruguaio mostra que sua formação, a partir da "herança colonial", tem se caracterizado pela consolidação de um modelo territorial centralista, que ainda se mantém em seus aspectos básicos. Os aspectos mais relevantes do modelo centralista são os profundos desequilíbrios entre o norte e o sul do Rio Negro, a ocupação perimetral do território, o esvaziamento permanente de suas áreas centrais e uma irracional expansão de sua área metropolitana.

O centralismo foi uma característica fundante da construção histórica do território uruguaio. O processo de integração da economia nacional ao mercado capitalista mundial teve como base o binômio campo-porto que foi decisivo para sua consolidação. O centralismo que estrutura o território nacional também se faz presente nos departamentos (províncias). O desenvolvimento de Montevidéu - a capital do país - aprofundou as diferenças campo-cidade durante todo o século $X X$. 
As diversas localidades urbanas no território podem ser classificadas em três categorias: a) o conglomerado metropolitano; b) as cidades intermediárias; e c) um amplo universo de pequenos e dispersos povoados. As cidades intermediárias, geralmente capitais departamentais, localizam-se na periferia do território nacional e estabelecem um sistema básico de colonização com suas correspondentes periferias. O esvaziamento do interior rural foi, e continua sendo, um dos principais problemas históricos do país.

A organização político-administrativa do Estado uruguaio está centralizada na sua capital. Esse modelo centralista que caracteriza a estrutura e funcionamento territorial seria, para o governo progressista, o argumento base para propor uma mudança "estrutural" da organização territorial do país e, para isso, se identificaram como desafios prioritários a serem abordados, a partir da nova lei de Ordenamento Territorial, as seguintes temáticas: a) novas formas e tecnologias na produção agropecuária (geralmente associadas ao mono cultivo e ao agronegócio); b) novas formas e tecnologias na produção energética que geram novos impactos territoriais (energia eólica, biomassa, etc.); c) processos de subutilização dos recursos disponíveis, geralmente associados a um mal manejo dos mesmos (solos produtivos, água, áreas turísticas, áreas protegidas, etc.); d) processos de concentração na propriedade da terra que aprofundam o esvaziamento das áreas rurais e sua transformação produtiva; e) expansão irracional das áreas urbanas periféricas, carentes em serviços e equipamentos básicos, esvaziamento das áreas urbanas consolidadas, geralmente equipadas e adequadamente servidas; f) acelerada fragmentação social dos territórios urbanos e crises contínuas de seus espaços públicos (qualidade, privatizações, deterioração, etc.); g) assimetrias pronunciadas entre distintas áreas do território (em população, recursos, acesso a serviços, mobilidade, etc.); e h) organização políticoadministrativa indiferente ao território real e a seu funcionamento (MIRANDA: SIENRA, 2008).

Independentemente dos desafios apontados pelo governo progressista, devem-se observar outras variáveis possíveis para uma análise das políticas adotadas no decorrer da década de 2000 sobre o ordenamento territorial atrelado ao desenvolvimento sustentável. Para além da lógica desenvolvimentista explicitada nos documentos e nas ações do governo progressista, as informações apontam para uma expansão do agronegócio no país, expansão esta que necessita de um arcabouço jurídico que Ihe ofereça legitimidade. Observe-se, como exemplo, o tema da propriedade da terra.

\section{A QUESTÃO DA PROPRIEDADE DA TERRA}

Observando o Quadro 3, pode-se analisar a compra e venda da terra para uso agropecuário no período de 2000 a 2009. Observa-se que o montante de operações de compra e venda tem seu momento de maior significação entre os anos de 2004 e 2008. Por que este aumento de compra e venda de terras destinadas ao uso agropecuário acontece nesse período? Uma primeira hipótese é a de que esse aumento de operações se relaciona com a expansão do agronegócio 
na Argentina e no Brasil. As datas coincidem justamente com o período em que as políticas desenvolvimentistas brasileiras e argentinas colocam em marcha a "reforma agrária de mercado".

Quadro 3. Compra e Venda de Terras para uso Agropecuário - 2000 - 2009

\begin{tabular}{|c|c|c|c|}
\hline ANO & $\mathbf{N}^{\circ}$ de Operações & $\begin{array}{c}\text { Total em milhares de } \\
\text { ha }\end{array}$ & $\begin{array}{c}\text { Total em milhões de } \\
\text { U\$S }\end{array}$ \\
\hline 2000 & 1.517 & 308 & 138 \\
\hline 2001 & 1.966 & 530 & 219 \\
\hline 2002 & 1.598 & 365 & 141 \\
\hline 2003 & 2.156 & 741 & 311 \\
\hline 2004 & 2.746 & 758 & 503 \\
\hline 2005 & 2.872 & 846 & 613 \\
\hline 2006 & 3.245 & 859 & 972 \\
\hline 2007 & 3.277 & 676 & 969 \\
\hline 2008 & 2.959 & 648 & 1.260 \\
\hline 2009 & 1.847 & 323 & 735 \\
\hline TOTAL & 24.183 & 6.089 & 5.878 \\
\hline
\end{tabular}

Fonte: Elaboração própria a partir de dados da Direção de Estatística Agropecuária - DIEA, Uruguai, 2010.

Vejamos quem são esses compradores e vendedores da terra. Segundo documento de trabalho da Direção de Estatísticas Agropecuária-DIEA do MGAP do Uruguai, no ano de 2009, 50\% da superfície total comercializada (162 mil hectares) foi vendida por uruguaios. As operações nas quais não foi possível conhecer a nacionalidade do vendedor - por não ser ele uma pessoa física representaram 38\% da superfície vendida, a um preço médio de U\$S 2.713 por hectare.

Quadro 4. Vendas de Terras para uso Agropecuário. Por nacionalidade do vendedor - 2009

\begin{tabular}{|c|c|c|c|}
\hline $\begin{array}{c}\text { Nacionalidade do } \\
\text { Vendedor }\end{array}$ & $\mathbf{N}^{\mathbf{0}}$ de Operações & $\begin{array}{c}\text { Total em milhares de } \\
\text { ha }\end{array}$ & $\begin{array}{c}\text { Total em milhões de } \\
\text { U\$S }\end{array}$ \\
\hline Uruguaio & 1.432 & 162 & 307 \\
\hline Argentino & 86 & 14 & 37 \\
\hline Brasileiro & 41 & 11 & 35 \\
\hline Outras & 32 & 13 & 38 \\
\hline Não Aplicável & 256 & 124 & 335 \\
\hline TOTAL & 1.847 & 323 & 753 \\
\hline
\end{tabular}

Fonte: Elaboração própria a partir de dados da Direção de Estatística Agropecuária - DIEA, Uruguai, 2010.

Um percentual de $34 \%$ da área vendida foi comprada por uruguaios e quase $60 \%$ foi adquirido por compradores cuja nacionalidade se desconhece por não se tratar de pessoas físicas. Essas operações com empresas acumularam U\$S 496 milhões, correspondentes a dois terços do montante total do período. 
Quadro 5. Compra de Terras para uso Agropecuário. Por nacionalidade - 2009

\begin{tabular}{|c|c|c|c|}
\hline $\begin{array}{c}\text { Nacionalidade do } \\
\text { Comprador }\end{array}$ & $\mathbf{N}^{\mathbf{0}}$ de Operações & $\begin{array}{c}\text { Total em milhares de } \\
\text { ha }\end{array}$ & $\begin{array}{c}\text { Total em milhões de } \\
\text { U\$S }\end{array}$ \\
\hline Uruguaio & 1.139 & 111 & 180 \\
\hline Argentino & 120 & 13 & 43 \\
\hline Brasileiro & 44 & 9 & 12 \\
\hline Outras & 57 & 5 & 21 \\
\hline Não Aplicável & 487 & 184 & 496 \\
\hline TOTAL & 1.847 & 323 & 753 \\
\hline
\end{tabular}

Fonte: Elaboração própria a partir de dados da Direção de Estatística Agropecuária - DIEA, Uruguai, 2010.

Os uruguaios venderam 50 mil hectares a mais do que compraram, enquanto que os compradores, cuja nacionalidade se desconhece, compraram 61 mil hectares a mais do que venderam. O preço de compra conseguido pelos brasileiros foi $240 \%$ menor que o preço pelo qual conseguiram vender suas terras.

Quadro 6. Compra de Terras para uso Agropecuário. Por situação jurídica - 2009

\begin{tabular}{|c|c|c|c|}
\hline $\begin{array}{c}\text { Condição Jurídica do } \\
\text { Comprador }\end{array}$ & $\mathbf{N}^{\circ}$ de Operações & $\begin{array}{c}\text { Total em milhares de } \\
\text { ha }\end{array}$ & $\begin{array}{c}\text { Total em milhões de } \\
\text { U\$S }\end{array}$ \\
\hline Pessoa Física & 1.348 & 137 & 250 \\
\hline Sociedade Anônima & 422 & 157 & 415 \\
\hline Outras Sociedades & 69 & 28 & 83 \\
\hline Estado & 8 & 1 & 5 \\
\hline TOTAL & 1.847 & 323 & 753 \\
\hline
\end{tabular}

Fonte: Elaboração própria a partir de dados da Direção de Estatística Agropecuária - DIEA, Uruguai, 2010.

Observa-se que as sociedades anônimas realizaram 422 operações de compra, em um total de 157 mil hectares (50\% do total das transações), numa média de 372 hectares por operação (Ver Quadro 6). As compras realizadas por pessoas físicas registraram uma média de 102 hectares por operação. As sociedades anônimas compraram terras a uma média de U\$S 2.645/ha, 14\% acima do preço médio geral.

Quadro 7. Venda de Terras para uso Agropecuário. Por situação jurídica do vendedor - 2009

\begin{tabular}{|c|c|c|c|}
\hline $\begin{array}{c}\text { Condição Jurídica do } \\
\text { Vendedor }\end{array}$ & $\mathbf{N}^{\mathbf{0}}$ de Operações & $\begin{array}{c}\text { Total em milhares de } \\
\text { ha }\end{array}$ & $\begin{array}{c}\text { Total em milhões de } \\
\text { U\$S }\end{array}$ \\
\hline Pessoa Física & 1.564 & 191 & 393 \\
\hline Sociedade Anônima & 200 & 113 & 300 \\
\hline Outras Sociedades & 69 & 19 & 58 \\
\hline Estado & 14 & 1 & 2 \\
\hline TOTAL & $\mathbf{1 . 8 4 7}$ & 323 & 753 \\
\hline
\end{tabular}

Fonte: Elaboração própria a partir de dados da Direção de Estatística Agropecuária - DIEA, Uruguai, 2010. 
As sociedades anônimas venderam 113 mil hectares, quase 35\% da superfície total vendida (Ver Quadro 7). As vendas realizadas pelas sociedades anônimas registraram um preço médio de U\$S 2.667, valor que se situa $15 \%$ acima da média geral.

O que resulta estranho é que o MAGP e seu aparelho burocrático não consigam identificar os compradores-vendedores das pessoas jurídicas, como se estas não tivessem uma nacionalidade definida, deixando óbvio que não há interesse de que essas informações sejam de domínio público. Os dados disponíveis não permitem identificar quais foram as outras partes que interviram nos contratos - de compra ou venda - realizados pelas pessoas jurídicas: se pessoas físicas ou jurídicas, se estrangeiros ou uruguaios (DIEA-MGAP, 2010) ${ }^{2}$.

Quadro 8. Preços de venda por hectare e por ano segundo escala de superfície 2003, 2006, 2009 - valor em U\$S - USA

\begin{tabular}{|c|c|c|c|}
\hline $\begin{array}{c}\text { Tamanho da } \\
\text { propriedade em ha }\end{array}$ & $\begin{array}{c}\text { Preço de Venda por } \\
\text { ha }\end{array}$ & $\begin{array}{c}\text { Preço de Venda por } \\
\text { ha }\end{array}$ & $\begin{array}{c}\text { Preço de Venda por } \\
\text { ha }\end{array}$ \\
\hline ANO & $\mathbf{2 0 0 3}$ & $\mathbf{2 0 0 6}$ & $\mathbf{2 0 0 9}$ \\
\hline Menos de 500 ha & 461 & 1.034 & 2.203 \\
\hline 501 a 2000 & 409 & 1.108 & 2.273 \\
\hline Mais de 2000 & 401 & 1.289 & 2.611 \\
\hline
\end{tabular}

Fonte: Elaboração própria a partir de dados da Direção de Estatística Agropecuária - DIEA, Uruguai, 2010.

A valorização da terra no período 2003 a 2009 deve-se a vários fatores e, particularmente, ao novo modelo de desenvolvimento rural adotado na região a partir das "recomendações" do Banco Mundial e suas organizações associadas. Pode-se observar que, no Uruguai, o valor da terra mudou desde que se disponibilizou para o latifúndio uma nova modalidade de negócios: a produção da agroindústria promovida a partir de políticas públicas, financiada pelo Estado e articulada com o capital internacional. Dessa forma, os campos não poderiam mais ficar ociosos e dedicados quase que com exclusividade para a criação extensiva de gado. O novo negócio, muito lucrativo, era intensificar o setor agroexportador.

No caso dos arrendamentos de terra para uso agropecuário, a situação, segundo o DIEA, foi a seguinte (Ver Quadro 9):

2 DIEA. Estadísticas Agropecuarias: Tierras de Uso Agropecuario: ventas y arrendamientos. Documento de Trabajo. Montevideo, 2010, p. 1-32. 
Quadro 9. Arrendamento de terras para uso agropecuário - 2000 - 2009

\begin{tabular}{|c|c|c|c|}
\hline ANO & $\mathbf{N}^{\circ}$ de Contratos & $\begin{array}{c}\text { Total em milhares de } \\
\text { ha }\end{array}$ & $\begin{array}{c}\text { Total em milhões de } \\
\text { U\$S }\end{array}$ \\
\hline 2000 & 1.131 & 415 & 11.724 \\
\hline 2001 & 1.166 & 407 & 10.770 \\
\hline 2002 & 1.287 & 476 & 11.204 \\
\hline 2003 & 1.440 & 561 & 16.297 \\
\hline 2004 & 1.577 & 574 & 21.199 \\
\hline 2005 & 1.423 & 536 & 20.163 \\
\hline 2006 & 1.547 & 540 & 25.509 \\
\hline 2007 & 2.222 & 826 & 49.904 \\
\hline 2008 & 2.820 & 1.116 & 137.867 \\
\hline 2009 & 2.091 & 727 & 73.733 \\
\hline TOTAL & 16.704 & 6.178 & 378.370 \\
\hline
\end{tabular}

Fonte: Elaboração própria a partir de dados da Direção de Estatística Agropecuária - DIEA, Uruguai, 2010.

Durante o ano de 2009, registraram-se 2.091 contratos, por um total de 727.000 hectares, a quase 74 milhões de dólares. O preço médio dos contratos registrados foi de U\$S 101/ha/ano, o que implicou uma queda de $18 \% \mathrm{com}$ relação a 2008. Nos dez anos transcorridos entre 2000 e 2009, registraram-se 16.704 contratos de arrendamento, por um valor de mais de 378 milhões de dólares. Nos anos de 2007 e 2008, acontece um aumento considerável no número de contratos, na superfície arrendada e no preço. (DIEA, 2010).

Em dezembro de 2010, a Vertente Artiguista realizou um seminário no balneário Las Cañas, na cidade de Rio Negro - Uruguai, tendo como tema "A terra - uso e posse". O movimento frenteamplista convidou vários especialistas da área e abriu um debate com a comunidade local. Entre os convidados, destacou-se a intervenção do Engenheiro Agrônomo Miguel Vasallo (ex-diretor do INC) que, na sua apresentação, fez destaque à questão do preço da terra e seu particular aumento entre 2003 e 2008.

O valor médio da terra, por hectare, nas décadas de 1980 e 1990, era de U\$S 400 e, entre 2003 e 2008, foi de U\$S 1.700. Assim, neste último período, vivenciou-se uma dinâmica no mercado de terras totalmente desconhecida, única em toda a história do país. Vasallo explicava esse processo como consequência de quatro fatores: a) a inserção internacional nos mercados mundiais, a mudança dos preços e o valor das commodities; b) a dinâmica expansiva da economia agrária do Brasil e da Argentina que, de diversas formas, ultrapassa fronteiras; c) o nível muito alto do investimento e as mudanças tecnológicas; e d) como razão complementar, as políticas econômicas e setoriais. "Se o país não tivesse um contexto de políticas macroeconômicas e algumas políticas setoriais não haveria conhecido esta dinâmica que não só mudou o setor agropecuário, senão que também, em boa medida, ao país" (VERTIENTE ARTIGUISTA, 2010, p. 6). 


\section{CONSIDERAÇÕES FINAIS}

Uma vez no governo nacional, a partir de 2004, a Frente Ampla se "adapta" às novas regras do jogo. Negocia com o Banco Mundial o modelo de desenvolvimento para o país antes mesmo de assumir o governo e começa a preparar as condições necessárias para a sua implantação. Esse modelo está voltado para o processo de acumulação de capital e, no meio rural, em particular, para "desenvolver" os setores agroexportadores por meio da reforma agrária de mercado.

A lógica do ordenamento territorial $\mathrm{e}$, consequentemente, do desenvolvimento territorial no Uruguai, vem a efetivar um modelo de desenvolvimento rural que tem como finalidade a financeirização do meio agrário por meio de uma nova institucionalidade que permite e legitima, essencialmente, duas coisas: a primeira é a incorporação do meio rural no sistema de negócios financeiros: novas instituições privadas ofertando crédito, fazendo agricultura de contratos, realizando negócios com o capital estrangeiro sob a forma de arrendamentos para o uso da terra, entre outros. A segunda, é o discurso legitimador do território. Uma vez que o desenvolvimento rural se planeja sobre uma base territorial (geralmente indefinida), sob o conceito de "território", ocultase o "latifúndio", eliminando-se, assim, um problema clássico do sistema fundiário uruguaio.

As referências às "estratégias de desenvolvimento territorial" no Uruguai encobrem os interesses do latifúndio. Acontece que, na nova lógica de ordenamento territorial, não se questiona a propriedade nem a posse da terra existente em um determinado território. Se o desenvolvimento territorial visa o crescimento econômico do território, ele está desenvolvendo os interesses do latifúndio. Assim, o problema continua o mesmo, só que, desta vez, o processo de desenvolvimento se apresenta como uma necessidade "nacional" que beneficiará a "todos" e que deve ser acolhida por toda a sociedade.

Como se pode observar ao longo do texto, o modelo de desenvolvimento uruguaio está voltado para os setores agroexportadores que, sob a lógica do desenvolvimento territorial, utilizam-se de dinheiro público para financiar o processo de desenvolvimento do latifúndio, fundamentalmente, com infraestrutura para a modernização de seus sistemas produtivos. Por outro lado, as populações que integram esses territórios encontram-se cada vez mais dependentes das cadeias produtivas e mais marginalizadas do processo de desenvolvimento, trazendo, consequentemente, maior grau de precarização nas relações de trabalho, maiores dificuldades de sobrevivência para os pequenos produtores e um crescente aumento nas desigualdades sociais.

\section{REFERÊNCIAS}

CABRAL, José Pedro C. A nova esquerda uruguaia: da oposição ao governo. São Leopoldo, Oikos, 2008. 
DIEA - DIRECCIÓN DE ESTADISTICAS AGROPECUÁRIAS. Estadísitcas Agropecuárias: Tierras de Uso Agropecuário: ventas y arrendamientos. Documento de Trabajo. Montevideo, 2010.

FRUGONI, Robert. La inclusión del desarrollo rural en las políticas públicas agropecuarias: un proceso imprescindible en marcha. In: Anuario Oficina de Planificación y Producción Agropecuaria - OPYPA 2008. Montevideo: MGAP DGDR, 2008.

GONZÁLEZ, Maria Noel; GÓMEZ, Jacqueline. Primer Encuentro Nacional de la Producción Agropecuaria Familiar. In: Anuário OPYPA, 2007. Montevideo: MGAP, 2007.

GONZÁlEZ, Maria Noel. Segundo Encuentro Nacional de la Producción Agropecuaria Familiar: un camino que se afirma. In: Anuário OPYPA 2009. Montevideo: MGAP, 2009.

MGAP - MINISTERIO DE GANADERIA, AGRICULTURA E PESCA. Anuário OPYPA, 2008.

MIRANDA, Adrían Rodríguez; SIENRA, Mariana, Claves del desarrollo local: el caso de Treita y Tres. Montevideo: Fin de Siglo, 2008.

MVOTYMA - MINISTERIO DE VIVIENDA, ORDENAMIENTO TERRITORIAL Y MEDIO AMBIENTE. Directrices Nacionales de Ordenamiento Territorial $y$ Desarrollo Sostenible: Aproximaciones Básica. Documento de Trabajo. Montevideo: 2010.

VASSALLO, Miguel; TADDEO, José Carlos. MGAP e INC juntos para un desarrollo rural con enfoque territorial. In: Anuário OPYPA 2009. Montevideo, 2009.

VERTIENTE ARTIGUISTA. La tierra uso y tenencia. Relatório do Seminário. Rio Negro, Frente Amplio, 2010.

Submetido em 07/07/2013

Aprovado em 02/06/2015

Sobre o autor

José Pedro Cabrera Cabral

Doutor em História pela Universidade do Vale dos Sinos - UNISINOS, São Leopoldo, Rio Grande do Sul. Professor do bacharelado em Relações Internacionais e do Mestrado em Geografia da Universidade Federal do Tocantins - Brasil.

E-mail: josepedro@uft.edu.br. 